\title{
Comentarios a las Observaciones Finales realizadas por el Comité de los Derechos del Niño y al Comité contra la Tortura
}

Este comentario, junto a los documentos que analiza, está disponible en www.anuariocdh.uchile.cl

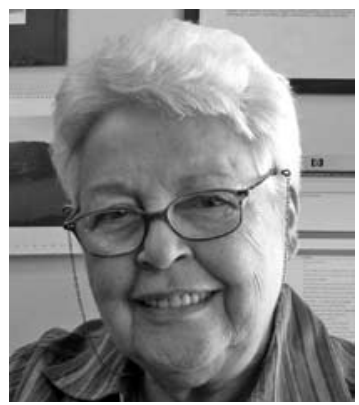

Cecilia Medina Quiroga

Co-Directora del Centro de Derechos Humanos. Abogada, Licenciada en Ciencias Jurídicas y Sociales por la Universidad de Chile, doctorada en Derecho en la Universidad de Utrecht, Holanda. Es profesora de Derecho Internacional de los Derechos Humanos de la Facultad de Derecho de la Universidad de Chile. Durante ocho años fue miembro del Comité de Derechos Humanos de las Naciones Unidas y Presidenta del mismo en los años 1999 y 2000. Fue jueza de la Corte Interamericana de Derechos Humanos desde el año 2002 al 2009.

cmedina@derecho.uchile.cl

\section{RESUMEN}

El artículo es un comentario sobre (I) las Observaciones Finales realizadas por el Comité de los Derechos del Niño a los informes presentados por Chile en cumplimiento del Protocolo Facultativo relativo a la Venta de Niños, la Prostitución Infantil y la Utilización de Niños en la Pornografía (CRC/C/OPSC/ $\mathrm{CHL} / \mathrm{CO} / 1)$ y del Protocolo Facultativo relativo a la participación de Niños en los Conflictos Armados (CRC/C/OPAC/CHL/CO/1) ambos de febrero de 2008', y a las (II) Observaciones finales hechas al quinto informe periódico presentado por Chile ante el Comité contra la Tortura (CAT/C/CHL/CO/5, 23 de junio 2009).

\section{Chile y sus niños y niñas}

A. Observaciones en el marco del artículo 12 del Protocolo Facultativo de la Convención de los Derechos del Niño relativo a la Venta de Niños, la Prostitución Infantil y la Utilización de Niños en la Pornografía

Sin perjuicio de que éste es un informe separado, el Comité lo examina como una unidad junto con el informe relativo a la Convención sobre los Derechos del Niño y el del Protocolo Facultativo sobre Participación de los Niños en Conflictos Armados y espera que el Estado así los trate.

Chile presentó su primer informe al Comité de los Derechos Niños en cumplimiento de su obligación en el Protocolo señalado, el 28 de enero de 2008 y el Comité aprobó sus Observaciones Finales el 1 de febrero de ese mismo año. Las Observaciones se dividen en las siguientes secciones: (i) Directrices Generales; (ii) Datos; (iii) Medidas Generales de Aplicación; (iv) Prevención de la

\footnotetext{
Para una referencia a las labores del Comité de los Derechos del Niño en su examen de los informes de los Estados, ver MEDINA, Cecilia. La situación de los Niños y Adolescentes en Chile a la Luz de las Observaciones del Comité de los Derechos del Niño de las Naciones Unidas al Tercer Informe Periódico de Chile. Anuario de Derechos Humanos 2008 (4) Centro de Derechos Humanos, Facultad de Derecho, Universidad de Chile, 2008.
} 
Venta de Niños, la Prostitución Infantil y la Utilización de Niños en la Pornografía; (v). Prohibición y Asuntos Conexos; (vi) Protección de los Derechos de los Niños Víctimas; (vii) Asistencia y Cooperación Internacionales; y (viii) Seguimiento y Difusión.

(i) Directrices Generales. Como es habitual, el Comité comienza su informe señalando los aspectos positivos encontrados en él. En el caso de Chile, destacó la aprobación de la Ley № 19.927 (2004) que modificó el Código Penal y tipificó nuevos delitos en las esferas de este Protocolo; la Ley $N^{\circ} 20.032$ (2005), que creó un sistema de apoyo a la niñez y adolescencia; y la Ley № 20.207 (2007) que estableció que el plazo de prescripción de los delitos sexuales contra menores se contará desde el día en que alcancen la mayoría de edad. También estimó positivos el Plan Nacional por un Buen Trato Infantil (2000-2006), el Marco para la Acción contra la Explotación Sexual Comercial, el Programa de Prevención y Eliminación de la Explotación Sexual Comercial Infantil (2002-2004) y la Política Nacional y Plan de Acción Integrado a favor de la Infancia y la Adolescencia (2000-2010).

Finalmente, considera digno de elogio que Chile haya ratificado el Protocolo Facultativo de la Convención sobre los Derechos del Niño relativo a la participación de los niños en los conflictos armados de 2003 -que forma parte de las normas que ese Comité debe supervisar-, y otros dos tratados: la Convención Internacional sobre la protección de los derechos de los trabajadores migratorios y de sus familiares de 2005, y el Convenio $N^{\circ} 182$ de la Organización Internacional del Trabajo sobre la prohibición de las peores formas de trabajo infantil y la acción inmediata para su eliminación de 2000, que son fiscalizadas por otros órganos, pero que muestra la integralidad del sistema de protección de los derechos humanos (párr. 4).

(ii) Datos. En los informes que se presentan a los diversos Comités de los tratados existentes en el marco de las Naciones Unidas, un aspecto esencial es el de los datos. Es muy importante que se muestren los avances y dificultades en cifras. El Comité lamentó en esta ocasión que Chile haya presentado datos tan limitados sobre la magnitud de los problemas de que trata el Protocolo, atribuyendo esta carencia a la falta de un sistema integral de reunión de datos y a los tabúes sociales relaciones con esos temas. Recomendó que se estableciera un sistema integral de reunión de datos, solicitando para el próximo informe un análisis sistemático de datos desglosados -entre otras categorías- por edad, sexo, grupo minoritario, contexto socioeconómico y zona geográfica. Eso permitiría al Comité evaluar la aplicación de las políticas (párrs. 7-8).

(iii) Medidas Generales de Aplicación. A pesar de los puntos positivos, el Comité tiene observaciones sobre algunos de ellos: la Ley № 19.927 que modifica el Código Penal y el Código Procesal Penal no se ajusta aún plenamente a las disposiciones del Protocolo, particularmente en lo relativo a la penalización de los delitos. En cuanto a los planes y programas implementados, el Comité recomienda que se mejore la coordinación en lo que diga referencia a este Protocolo y que se haga una evaluación sistemática con los agentes pertinentes, la sociedad civil y los niños víctimas de estos delitos (párrs. 9-13).

El Comité hace tres grandes recomendaciones a este respecto: la primera es que intensifique la educación y la capacitación sistemáticas de los grupos profesionales que se relacionan con los temas del Protocolo; que intensifique la difusión del Protocolo en la población, especialmente niños y padres; y que promueva la sensibilización del público en general respecto de las medidas preventivas y de los efectos perjudiciales de estos delitos, dando particular atención a los niños (párr. 14).

La segunda es que el Estado brinde información más sistemática sobre las asignaciones presupuestarias para la aplicación del Protocolo y que proporcione todos los recursos necesarios para la prevención, protección, recuperación física y psicológica de las víctimas, así como la investigación y el enjuiciamiento de los responsables. El enfoque deberá estar basado en los derechos 
humanos y se centrará en los niños, "en particular con respecto a la formulación y ejecución de estrategias y políticas de reducción de la pobreza" (párr. 16).

La tercera, al Comité le preocupa la inexistencia de una institución nacional independiente de derechos humanos -algo que ya había hecho saber a Chile en sus Observaciones Finales al tercer informe periódico de Chile en el marco de la Convención sobre los Derechos del Niño-, a la luz de su Observación general No. $2(2002)^{2}$ y de los Principios de París. Esta es una clara referencia a la institución conocida con el nombre de Ombudsman, que, en este caso, debe tener "competencia técnica en materia de derechos del niño, extender su presencia a todo el territorio nacional, y estar dotada de personal adecuadamente formado que sea capaz de atender las denuncias teniendo en cuenta la sensibilidad del niño y asegurar que los niños tengan un fácil acceso a dicho mecanismo independiente de denuncia en caso de violaciones de sus derechos, en particular [pero no exclusivamente] los contemplados en el Protocolo Facultativo" (párr. 18).

(iv) Prevención. El Comité se preocupa por el escaso conocimiento de la existencia de la pornografía infantil en el Estado Parte, el aumento de la prostitución de los niños varones y el aumento de los casos de turismo sexual en el país (párr. 19). Recomienda nuevamente medidas adecuadas para responder a estos flagelos. En cuanto al turismo sexual pide campañas de sensibilización para los turistas y una cooperación estrecha con los operadores de viajes, las ONG y las organizaciones de la sociedad civil.

El Comité no puede dejar de asociar estos problemas con el aumento de la pobreza y del abuso sexual y su consiguiente impacto en el aumento de la explotación sexual comercial. Por ello, recomienda a Chile ocuparse con mucha atención de las causas fundamentales del problema: pobreza, subdesarrollo y las actitudes culturales de la sociedad (párrs. 21 y 22).

(v) Prohibición. El Comité se preocupa de que la venta de niños, todas las formas y tipos de trata y la posesión de pornografía infantil no estén plenamente tipificadas en Chile y que el marco jurídico no sea claramente suficiente para tratar la adopción de niños en violación de los instrumentos jurídicos aplicables en esa materia (párr. 23), por lo que recomienda que se corrijan estas deficiencias y se ratifique la Convención Interamericana sobre Tráfico Internacional de Menores (párr. 24).

En esta misma materia, el Comité no está satisfecho con el hecho de que no haya mejorado el sistema de seguimiento judicial de todas las denuncias de perpetración de estos delitos y que Chile sólo puede ejercer jurisdicción extraterritorial sólo respecto de algunos de los delitos, siempre que el autor o la víctima sean chilenos, lo que debe ser subsanado (párrs. 25-27).

(vi) Protección. Al Comité le inquieta que las mejoras procesales a fin de proteger a los niños no se apliquen siempre adecuadamente y que sea posible que los niños utilizados en la prostitución y la pornografía no siempre sean considerados víctimas, sino que pueden a veces considerarse delincuentes. Esto también debe ser solucionado (párrs. 29-30).

También es preocupante la falta de mecanismos sistemáticos y coordinados a nivel nacional que se ocupen de los derechos y las necesidades de los niños víctimas, a pesar de que encuentra positivas las medidas adoptadas en la esfera de la recuperación y reintegración de los mismos (como el proyecto "Mar'kaza") (párrs. 32-32).

Otros puntos de preocupación son los niños que podrían tener derecho a refugio por ser víctimas, pero que no lo son por falta relegislación adecuada. Esto requeriría una ley general de refugiados.

2 La Observación General No. 2 del Comité de los Derechos del Niño explica las características que debe poseer este tipo de órganos. Ver CRC/GC/2002/2 15 noviembre 2002. 
Ayudaría a todo eso la ratificación de la Convención sobre el Estatuto de los Apátridas de 1954 y la Convención para reducir los casos de apatridia de 1961 (párrs. 33-35).

(vii) Asistencia y Cooperación Internacionales. El Comité considera importante que se dé asistencia y haya cooperación en el ámbito internacional, mencionando la creación del Comité de Frontera Chile-Bolivia que se ocupa del contrabando, la trata y la explotación sexual de niños y adolescentes y el acuerdo Niñosur para la prevención, detección, investigación, enjuiciamiento y castigo de los responsables de estos delitos y alentó al Estado a mantener su cooperación con los organismos y programas pertinentes de las Naciones Unidas.

(viii) Seguimiento y Difusión. Las recomendaciones del Comité deben ser transmitidas a los ministerios gubernamentales, al Congreso y a las autoridades locales para que todos tomen las medidas apropiadas para garantizar su aplicación. El informe de Chile, sus respuestas presentadas por escrito y estas observaciones deben también ser difundidas por Internet y por otros medios, al público en general.

\section{B. Observaciones en el marco del artículo 8 del Protocolo Facultativo de la Convención de los Derechos del Niño relativo a la Participación de Niños en los Conflictos Armados}

Chile presentó su primer informe al Comité de los Derechos del Niño en cumplimiento de su obligación en el Protocolo señalado el 28 de enero de 2008 y el Comité aprobó sus Observaciones Finales el 1 de febrero de ese mismo año. Las Observaciones son breves y comienzan, como las anteriores, con los aspectos positivos encontrados en el informe chileno, entre los cuales se destaca el hecho de que por ley se impide a los menores de 18 años participar en hostilidades y que no hay reclutamiento obligatorio antes de esa edad (párr. 4). El Comité espera que se establezca claramente en la ley que esta prohibición de reclutamiento obligatorio de los menores de edad no se aplica tampoco en casos de estado de guerra o de emergencia pública (párr. 14). Por otra parte, le preocupa que ya a los 12 años los niños se puedan matricular en escuelas premilitares (párr. 10). También alienta a Chile a terminar con la posibilidad del reclutamiento voluntario de los adolescentes de 17 o 18 años y, en casos excepcionales, aún los de 16 (párrs. 15-16).

Para fortalecer las medidas internacionales, el Comité recomienda a Chile que tipifique como delito el reclutamiento y participación de niños en hostilidades, establezca una jurisdicción extraterritorial para esos delitos, vele porque los códigos, manuales y demás directrices militares sean compatibles con el Protocolo y ratifique el Estatuto Penal Internacional (párr. 18). Esto último es ya una realidad, puesto que Chile depositó su instrumento de ratificación el 30 de junio de 2009. Solicita también a Chile que refuerce su asistencia y cooperación internacionales, por ejemplo, introduciendo una prohibición específica de venta de armas a países que recluten o utilicen niños en las hostilidades (párr. 27).

En cuanto a los problemas encontrados, el Comité advierte que este Protocolo no ha sido dado a conocer al público en general y a los niños en particular, ni que haya al parecer actividades de capacitación destinadas a los miembros de las Fuerzas Armadas y personal militar en general, así como a determinados grupos de profesionales (maestros, medios de comunicación, las autoridades que se ocupan de niños de otros países afectados por conflictos armados, jueces, abogados y policía). Esto debe subsanarse (párrs. 6-7).

El tema de los refugiados vuelve a citarse, como en las Observaciones anteriores, esta vez respecto de los niños que provienen de países en conflicto como colombianos y palestinos procedentes de Irak. El Comité espera que se adopten medidas especiales respetuosas de su cultura para su recuperación e integración (párrs. 21-24). 
En otro aspecto, pide a Chile que apresure la aprobación de la reforma del Código de Justicia Militar para limitar su competencia y dejar fuera de ella a la población civil (párrs. 20-21) e insiste en la necesidad ineludible de que se establezca una institución nacional independiente que ofrezca un mecanismo de denuncia y reparación accesible a los niños y recomienda que se acelere su establecimiento (párrs. 8-9).

\section{Conclusiones}

Si uno observa las Observaciones hechas a Chile por el Comité de los Derechos del Niño en el año 2007, se ve que se repite el tema de la discriminación por pobreza y la falta de efectividad y eficacia de las instituciones nacionales establecidas para la protección de los menores. Se observa en él y en las observaciones recién comentadas, la interdependencia de todos los derechos humanos, civiles y políticos y económicos, sociales y culturales, para salvaguardar la dignidad de todos los seres humanos, y en estas observaciones, la de los niños y adolescentes.

Como es fácil de advertir, con respecto al primero de los Protocolos Chile tiene todavía mucho que avanzar y lo que naturalmente dificulta el avance es la enorme brecha económica que hace a los niños pobres un sector extraordinariamente vulnerable a estas prácticas que, sin duda, pueden a menudo destruir sus vidas para siempre.

Respecto al segundo Protocolo la situación de Chile es bastante más favorable y está más cerca de cumplir con todas sus obligaciones, puesto que no está en una situación de conflicto armado. Es posible que sea necesario que el país perciba con más intensidad la importancia de la universalidad de las normas de protección de los derechos humanos, volcándose hacia el ámbito internacional particularmente en el campo de los niños y adolescentes, ya que esa es la garantía última para ayudar al logro de un mundo más armónico en el futuro.

\section{La Tortura: un tema siempre presente}

\section{A. Comentarios a las Observaciones Finales hechas al quinto informe periódico presentado por Chile ante el Comité contra la Tortura (CAT/C/CHL/CO/5, 23 de junio 2009)}

Chile ha estado moroso en el cumplimiento de las obligaciones internacionales que emergen de su calidad de Estado Parte de la Convención Contra la Tortura y Otros Tratos o Penas Crueles, Inhumanos o Degradantes. Debió haber presentado su tercer informe en 1997 y lo presentó recién el año 2004, por lo cual agrupó el tercer y cuarto informes en un documento. El quinto informe debió haberse presentado a más tardar el 29 de octubre de 2005, pero se envió sólo para ser considerado en el período de sesiones de mayo de 2009, es decir, casi cuatro años después. Las Observaciones finales sobre este informe fueron adoptadas por el Comité el 23 de junio de 2009.

¿Qué ha informado Chile sobre sus avances en estos años? En el campo internacional ratificó el Protocolo Facultativo a la Convención, que entró en vigencia para este país el 11 de enero de 2009. El objetivo de este Protocolo ${ }^{3}$ es establecer un sistema de visitas regulares realizadas por un órgano internacional y nacional a los lugares donde se encuentren personas privadas de libertad, con el fin de prevenir la tortura y otros tratos o penas crueles, inhumanos o degradantes. El cuerpo que realiza las visitas es un Subcomité para Prevención de la Tortura y de Otros Tratos o Penas Crueles, Inhumanos o Degradantes, creado por el Protocolo, que forma parte de la Organización de las Naciones Unidas y cada Estado tendrá la obligación de crear un cuerpo nacional para el mismo propósito (párr. 3). Chile todavía no lo ha hecho.

3 El Protocolo Facultativo de la Convención Contra la Tortura y Otros Tratos o Penas Crueles, Inhumanos o Degradantes fue adoptado el 18 de diciembre de 2002 y entró en vigencia el 22 de junio de 2006. 
En el campo nacional, la reforma del Código Procesal Penal fue también un factor positivo a los ojos del Comité, así como la creación de una unidad dentro del Programa de Derechos Humanos del Servicio Médico Legal que se dedicará a la implementación del Manual sobre la Investigación y Documentación Efectivas de la Tortura y Otros Tratos o Penas Crueles, Inhumanos o Degradantes (Protocolo de Estambul). Sin embargo, el Comité sostiene que al parecer la implementación no ha alcanzado a todo el personal médico y no se ha dado la debida importancia a los exámenes médicos para que ellos cumplan con el Protocolo (párr. 20). El resto de los aspectos positivos se refieren a los esfuerzos que estaría llevando a cabo Chile para cumplir con los demás compromisos que emergen de la Convención. Uno de ellos es su tarea de recomponer el pasado con la búsqueda de la verdad y el aseguramiento de reparaciones a las víctimas de la dictadura (párrs. 4-9).

La lista de los temas principales de preocupación y de las recomendaciones es larga y comienza con la definición, castigo e imprescriptibilidad de la tortura. El Comité estima que el Código Penal chileno no contiene una definición de tortura que sea compatible con la que establece el artículo 1 de la Convención, preocupación que ha manifestado ya con anterioridad, ni incluye como punible la tentativa de tortura; tampoco considera compatible con la Convención que exista una prescripción de 10 años para este delito y recomienda que sea abolida la norma que hoy existe (párrs. 10 y 11 ).

Junto con aprobar positivamente la información dada por el Estado de que la Convención está siendo invocada de manera directa ante los tribunales de justicia nacionales en el caso de víctimas de prisión política y tortura y de que la Corte Suprema ha dictado sentencias en que establece la no aplicabilidad del Decreto-ley de amnistía en este mismo tipo de casos, citando normas de tratados internacionales, el Comité lamenta que la vigencia de ese Decreto-ley deje los casos absolutamente al criterio de los tribunales nacionales y que no se haya seguido la decisión de la Corte Interamericana de Derechos Humanos en el caso Almonacid Arellano y otros ${ }^{4}$. Además, ha tenido noticias de que recientes decisiones de la Corte Suprema toman al parecer en cuenta el Decreto-ley para disminuir las penas que corresponderían a crímenes tan severos ${ }^{5}$. El Comité Ilama la atención de Chile al párrafo 5 de su Observación General No. 2 que instruye sobre la aplicación del artículo 2 de la Convención ${ }^{6}$ (párr. 12). Su recomendación es, por consiguiente, que Chile derogue ese Decreto-ley y que ponga fin a toda impunidad. En este sentido, pide también que se derogue la norma de la Ley №19.992 que establece la confidencialidad de la información sobre la tortura por un lapso de 50 años (párr. 19).

El Comité valora la preocupación del Estado por la salud de las víctimas de tortura y los diversos programas implementados para asistir a las víctimas, pero recomienda que este derecho a asistencia se haga efectivo para los que no residen en Chile, por ejemplo, por medio de acuerdos de cooperación con los Estados donde las víctimas residen. Aparece aquí también la perspectiva

4 Corte IDH. Caso Almonacid Arellano y otros Vs. Chile. Excepciones Preliminares, Fondo, Reparaciones y Costas. Sentencia de 26 de septiembre de 2006. Serie C No. 154

5 Esto es lo que se llama en Chile la aplicación de la "media prescripción".

6 En el párrafo 5 el Comité: "Resalta que los Estados Partes en ningún caso podrán invocar circunstancias excepcionales para justificar actos de tortura en ningún territorio que esté bajo su jurisdicción. Entre esas circunstancias, la Convención señala el estado de guerra o la amenaza de guerra, la inestabilidad política interna o cualquier otra emergencia pública, por ejemplo, una amenaza de actos terroristas o delitos violentos, o un conflicto armado, tenga o no carácter internacional. Preocupan profundamente al Comité, que los repruebe absolutamente, los esfuerzos que realizan los Estados para justificar la tortura y los malos tratos como medio para proteger la seguridad pública o evitar las emergencias en éstas o cualquier otra situación. El Comité rechaza igualmente toda justificación fundada en la religión o en la tradición de la infracción de esta prohibición absoluta. El Comité considera que las amnistías u otros obstáculos que impiden enjuiciar y castigar con prontitud e imparcialidad a los autores de actos de tortura o malos tratos, o ponen de manifiesto una falta de voluntad al respecto, infringen el carácter imperativo de la prohibición". (OBSERVACIÓN GENERAL N² 2. Aplicación del artículo 2 por los Estados Partes CAT/C/GC/2, 24 de enero de 2008). 
de género, ya que el Comité urge a Chile a incorporar una política de género que comprenda capacitación y desarrollo de la conciencia de los oficiales responsables de manejar los casos de víctimas de asalto o violencia sexual (párr. 18). También le preocupa el hecho de que haya aún personas que debieron ir al exilio después de ser torturados y no pueden volver al país y espera que Chile reconsidere el estatus de esas personas y considere la posibilidad de que se les permita su retorno (párr. 24).

Algunas de las preocupaciones del Comité han sido atendidas por Chile. La primera se refiere al restablecimiento de la comisión que determinó la calidad de prisionero/a político/a o torturado/a (Comisión Valech) que el Comité considera no había cumplido plenamente con su objetivo inicial y pide que se reabra (párr. 17). La otra es la solicitud del Comité de la creación de un instituto de derechos humanos (párr. 16). La muy reciente creación del Instituto Nacional de Derechos Humanos ${ }^{7}$ pretende solucionar ambos reparos.

En cuanto al primero, el artículo 3 de la Ley que crea el Instituto dispone que el "Presidente de la República establecerá una Comisión Asesora para la calificación de Detenidos Desaparecidos, Ejecutados Políticos y Víctimas de Prisión Política y Tortura, en adelante 'la Comisión', cuyo objeto exclusivo será calificar, de acuerdo a los antecedentes que se presenten y para el solo efecto de esta ley, a ciertas personas". De acuerdo a los criterios que allí se establecen, la comisión se disolverá automáticamente una vez que haya cumplido con sus funciones. En cuanto al segundo, es preciso que el Instituto se establezca conforme a sus disposiciones legales, para poder apreciar si cumple en la realidad con las exigencias de autonomía que los Principios de París a los que se refiere el Comité.

El problema de la tortura no es sólo algo del pasado. Preocupan al Comité las alegaciones de torturas cometidas hoy por funcionarios de la policía y también que haya limitaciones legales para publicar este tipo de noticias. Por ello, recomienda reformas legislativas relativas a la supervisión de la fuerza policial para asegurarse de que estos delitos no se cometan. Sugiere programas educacionales para prevenirla y un mecanismo para que la investigación de los actos de tortura que se perpetren sea efectiva y transparente con el fin de no permitir la impunidad (párr. 13). Con este fin, recomienda apurar la creación del Ministerio de Seguridad Pública para que éste supervise a Carabineros y a Investigaciones.

También Chile debería apresurar la reforma del Código de Justicia Militar, no sólo en materia de jurisdicción, sino que eliminando además el principio de la obediencia debida (párr. 14). Las condiciones de las prisiones en Chile preocupan al Comité, así como el maltrato y los castigos injustos que se ordenan en aplicación del régimen disciplinario. Se requiere un mejoramiento de las condiciones de prisión, el establecimiento de medidas de seguridad que respeten la dignidad de los presos (lo que implica terminar con las celdas de aislamiento) y el establecimiento del órgano y mecanismo que se ordena en el Protocolo Facultativo citado anteriormente (párr. 21).

Los adolescentes en prisión atraen la atención particular del Comité, ya que hay informes de serio hacinamiento, falta de separación de las diferentes categorías de los internos, inadecuada provisión de servicios básicos y uso excesivo de la fuerza y del aislamiento como formas de castigo. El Comité recuerda al Estado que la privación de libertad es una medida de última instancia y da algunas directrices sobre el tratamiento que éstos deben recibir de acuerdo con los estándares internacionales ${ }^{8}$ (párr. 22).

7 El Instituto fue creado por la Ley N²0.405 de 2009.

8 Para una guía de lo que se exige al Estado en cuanto a los niños y adolescentes en privación de libertad, véase Corte IDH. Caso Instituto de Reeducación del Menor Panchito López Vs. Paraguay, sentencia de 2 de septiembre de 2004, Serie C No. 112. 
Los indígenas son también tratados de manera particular, especialmente por los diversos informes sobre la continua comisión de actos de abuso de las fuerzas policiales contra ellos, incluyendo mujeres, niños y ancianos y por la aplicación de la Ley antiterrorista en respuesta a actos de protesta social. El Comité solicita datos estadísticos, divididos por edad, sexo y lugar geográfico de todas las quejas de tortura o malos tratos que habrían perpetrado sus funcionarios de la policía y de las correspondientes investigaciones, juicios y sentencias, así como también de los casos en que se ha aplicado la ley antiterrorista contra indígenas (párr. 23).

El último punto que trata el Comité es el tema de las reparaciones de las víctimas y sostiene que ésta debe alcanzar, entre otros, a las víctimas que residen fuera del país (párr. 25). Dada la importancia de ciertas recomendaciones (párrs. 12-14, 18 y 25), se pide a Chile que informe las medidas adoptadas dentro del plazo de un año (párr. 28).

Como siempre, el Comité solicita que el informe del Estado y estas observaciones finales sean difundidas ampliamente, también en los posibles idiomas indígenas, a través de los medios de comunicación, las páginas de Internet oficiales y de las organizaciones no gubernamentales (párr. 27).

\section{B. Conclusiones}

No es extraño que el tema de la tortura siga siendo preocupación del Comité en un país como Chile, que vivió diecisiete años de dictadura. Chile ha avanzado en ese respecto, pero todavía queda tarea por realizar.

Lo que preocupa más, sin embargo, es que las torturas y los tratos inhumanos o crueles se sigan perpetrando, no ya en un contexto de dictadura, sino de democracia. El trato en las prisiones, de adultos y de niños y adolescentes; el tratamiento de los indígenas; la conducta de la policía cuando ejerce sus funciones de resguardar el orden público, son aspectos que, si no se mejoran, impedirán que se pueda hablar en Chile de un verdadero respeto por los derechos humanos. La solución no depende sólo del órgano Ejecutivo, sino que también del Legislativo y sería altamente conveniente que el Ejecutivo -que es quien encabeza las relaciones con los órganos internacionales- comenzara a preocuparse de hacer llegar a otros órganos del Estado el mensaje de que la responsabilidad internacional se puede generar por la acción u omisión de cualquier agente del Estado, por lo cual se hace imperativo la capacitación de todos ellos en el derecho internacional de los derechos humanos. 